\title{
A Comprehensive Review of the Fabella Bone
}

\author{
Dominic Dalip ${ }^{1}$, Joe Iwanaga ${ }^{1}$, Rod J. Oskouian ${ }^{2}$, R. Shane Tubbs ${ }^{3}$ \\ 1. Seattle Science Foundation, Seattle, USA 2. Swedish Neuroscience Institute, Seattle, USA 3. Neurosurgery, Seattle \\ Science Foundation, Seattle, USA
}

Corresponding author: Joe Iwanaga, iwanagajoeca@gmail.com

\section{Abstract}

The fabella is a sesamoid bone that is embedded in the lateral head of the gastrocnemius muscle and often articulates directly with the lateral femoral condyle. It is present in 10-30\% of the general population with a higher incidence in Asians. The fabella can lead to various pathologies such as fabella pain syndrome and common fibular nerve palsy. Conservative treatment involves physical therapy or injecting local anesthetics or steroids around this bone. However, if symptoms persist, then a fabellectomy can be performed. Physicians should be aware of the fabella bone and the multiple pathologies associated with it in order to provide the best treatment and management for patients.

Categories: Pathology, Orthopedics

Keywords: sesamoid, knee pain, gastrocnemius, femoral condyle, fabellectomy, shock wave therapy, anatomy, variations

\section{Introduction And Background}

The patella is the largest and most well-known sesamoid bone. Other normally found sesamoid bones are seen in the hands and feet. A relatively unknown sesamoid bone of the leg is the fabella (Figures 1, 2). This sesamoid bone is embedded in the lateral head of the gastrocnemius muscle and often articulates directly with the lateral femoral condyle. The fabella's main function is thought to be stabilization of the medial femoral condyle and the fabella complex, which is made up of the plantaris and gastrocnemius muscles and the arcuate, fabellofibular, fabellopopliteal, and oblique popliteal ligaments [1-3].

Received 05/25/2018

Review began 05/30/2018 Review ended 05/31/2018 Published 06/05/2018

๑) Copyright 2018

Dalip et al. This is an open access article distributed under the terms of the Creative Commons Attribution License CC-BY 3.0., which permits unrestricted use, distribution, and reproduction in any medium, provided the original author and source are credited.

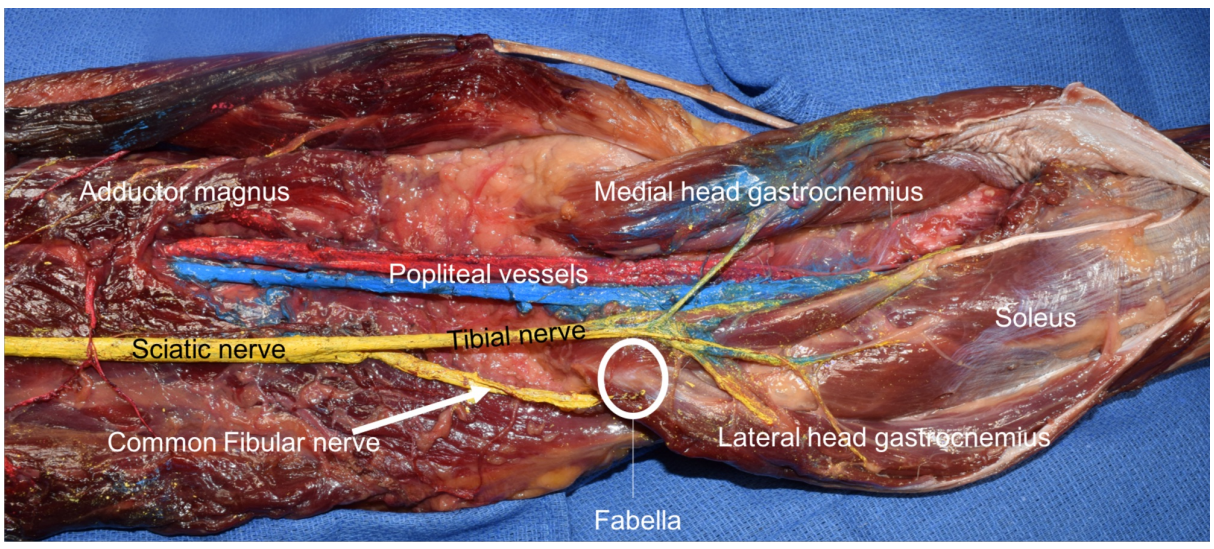

FIGURE 1: Posterior view of the distal left thigh and proximal leg.

Note the fabella as seen within the proximal tendon of the lateral head of the gastrocnemius.

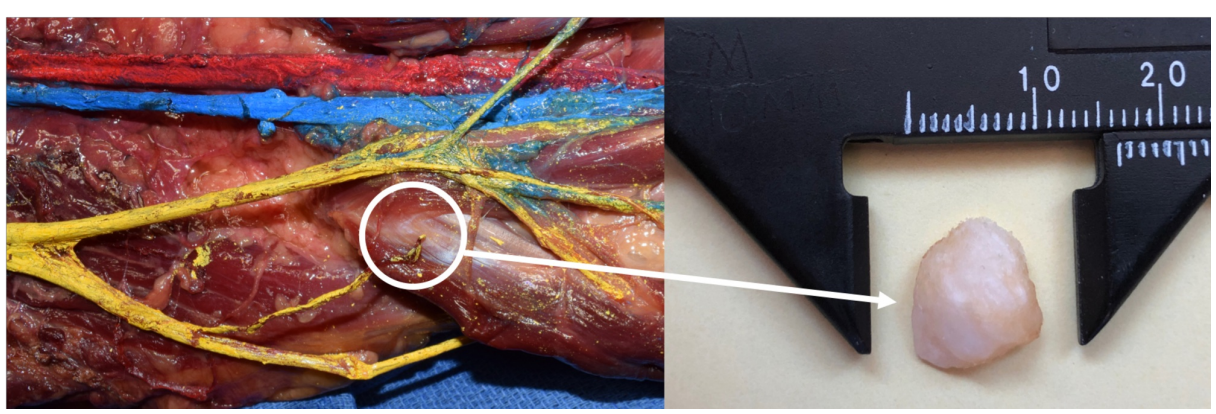


FIGURE 2: Zoomed in view of Figure 1 noting the fabella (circle).

After removal (right image), the fabella was found to be bony in nature and approximately $1 \mathrm{~cm}$ in diameter.

Various pathologies have been attributed to the presence of a fabella such as fabella pain syndrome, common fibular (CF) nerve palsy, fabella fracture, and Popliteal Artery Entrapment Syndrome (PAES) $[4,5]$. Therefore, the aim of this paper is to review the anatomy of the fabella and its related pathologies and treatment.

\section{Review}

\section{Anatomy}

The fabella usually ranges from $5 \mathrm{~mm}$ to $20 \mathrm{~mm}$ in diameter (Figure 2) and occupies about 26\% of the length of the CF nerve across the length of the lateral gastrocnemius. It is found in approximately $10 \%$ to $30 \%$ of the population and it occurs bilaterally in approximately $80 \%$ of cases $[1,6,7]$. In the Asian population, the fabella has a reported prevalence of $25 \%$ to $87 \%$ [2, 3, 7, 8]. The rates of a bilateral fabella were almost identical in Asian and non-Asian populations due to the differences in radiological and anatomical studies [3]. In radiological studies, the prevalence of the fabella was similar for both age and sex in the general population [9]. Males had a fabella frequency of $21.2 \%$ whereas females had a frequency of $27.2 \%$ and that there were no significant sex-based differences [1]. A gross anatomical study found that the occurrence of the fabella was $68.6 \%[3,7]$. Physicians can mistake the fabella for loose bodies or osteophytes which are usually asymptomatic in patients.

The fabella can be bony or cartilaginous. From 150 fabellae that were studied, 72 were cartilaginous and 27 were bony [7]. These results suggest that the fabella is formed by endochondral ossification. The consensus is that a sesamoid bone is formed from mechanical stress on a tendon [10-12]. The fabellofibular ligament and the fabella are formed from an evolutionary standpoint where humans moved from a quadrupedal to a bipedal posture [13].

A total of 102 knees of 51 cadavers were examined to determine the morphology of the fabella and the CF nerve in the popliteal region [3]. The fabella occupies about $26 \%$ of the length of the CF nerve across the length of the lateral head of the gastrocnemius [2,3]. This study found that the CF nerve adjacent to the fabella was wider and thinner compared to the proximal fabella in cases where the nerve was passing posterior and lateral to the fabella. In other cases where the CF nerve passed medial to the fabella, or when the fabella was absent, there were no differences in the size of the nerve as it passed adjacent to the fabella.

In cases of CF palsy, $20.8 \%$ of patients had the nerve located posterior to the fabella [8]. There were only a few cases of CF palsy in obese populations [14]. Therefore, some have posited that the less subcutaneous fat there is, the more prone the CF nerve is to compression by the fabella.

\section{Pathology and diagnosis}

Fabella pain syndrome should be considered as a differential diagnosis when a patient presents with persistent posterolateral knee pain, which could also be due to meniscal tears, lateral ligament instability, Baker's cyst, and proximal tibiofibular joint hypomobility [3, 15-20]. Patients with Fabella pain syndrome usually complain that the posterolateral knee pain is worse on fully extending the legs at the knee joint [21].

Fracture of the fabella is a rare entity but can happen due to direct trauma or chronic stress forces [5]. Three cases of stress fracture of the fabella were reported following total knee arthroplasty [18, 22]. These fractures varied from four months to nine years after surgery. Patients presented with swelling and pain of the posterolateral aspect of the knee. CT or MRI confirms the diagnosis and guides therapy.

The fabella is a cause of CF nerve palsy [14]. Seven cases were reviewed where the fabella compressed the CF nerve [23]. Three of the cases were treated surgically with fabellectomy and showed dramatic improvement in symptoms as soon as the first postoperative day. The other four cases were managed conservatively and showed improvement three to four days after treatment. Overall, improvement was seen between two weeks to two months after treatment.

PAES is a term that was first introduced by Love and Whelan in 1965 [24]. This syndrome occurs when the popliteal artery is compressed by musculotendinous structures in the popliteal fossa. Recurrent compression of the popliteal artery can lead to intimal damage, distal embolization, thrombosis, post-stenotic dilation and true aneurysms. The first known case of fabella pain syndrome with PAES was in a patient presented with intermittent claudication and severe knee osteoarthritis due to the fabella compressing the popliteal artery [24]. This was diagnosed using CT angiography which showed left popliteal artery occlusion without development of a collateral circulation. In this case, the treatment was fabella resection with revascularization of the popliteal artery. A better understanding of the anatomy of the knee and its 


\section{Treatment}

Fabella pain syndrome can be treated with physical therapy, injection of local anesthetics or steroids near the site, radial extracorporeal shock wave therapy (rESWT) or fabellectomy [6]. Physical therapy entails the patient be placed in a prone position with the legs supported at an angle of 30 degrees flexion [15]. Sustained pressure on the skin and deeper soft tissue is then applied along the directions of mobility restrictions incorporating the gastric-soleus complex and then the lateral head of the gastrocnemius is gently stretched. This technique is performed for approximately three minutes. The patient usually experiences immediate pain-free motions with flexion of the knee of up to 120 degrees.

rESWT entails three thousand shock waves being delivered at a frequency of $12 \mathrm{~Hz}$. This procedure can be performed at two-week intervals for a total of one to four times. The mechanism of rESWT involves destruction of the unmyelinated sensory nerves, hyperstimulation analgesic effect, and neovascularization in degenerated tissues. In one series, post treatment, patients noticed a sudden decrease in pain intensity: in three cases, pain intensity ranged from an eight to a one; and in one case, pain intensity ranged from a four to a zero. These decreases in pain intensity scale remained at a two-month follow-up clinical visit.

\section{Conclusions}

The fabella is a variant sesamoid bone that can lead to various pathologies such as fabella pain syndrome, CF nerve palsy, and popliteal entrapment syndrome. It is important for physicians to be aware of the fabella because it can be mistaken for osteophytes or loose structures that the surgeon may explore and that may put the patient at risk of neurovascular injuries. Also, the fabella is a rare cause of persistent posterolateral knee pain that physicians should be aware of as a differential diagnosis. A better understanding of the anatomy of the knee and its variations is important in diagnosing and treating patients with pathology of this area.

\section{Additional Information}

\section{Disclosures}

Conflicts of interest: In compliance with the ICMJE uniform disclosure form, all authors declare the following: Payment/services info: All authors have declared that no financial support was received from any organization for the submitted work. Financial relationships: All authors have declared that they have no financial relationships at present or within the previous three years with any organizations that might have an interest in the submitted work. Other relationships: All authors have declared that there are no other relationships or activities that could appear to have influenced the submitted work.

\section{References}

1. Phukubye P, Oyedele O: The incidence and structure of the fabella in a South African cadaver sample . Clin Anat. 2011, 24:84-90. 10.1002/ca.21049

2. Minowa T, Murakami G, Kura H, Suzuki D, Han SH, Yamashita T: Does the fabella contribute to the reinforcement of the posterolateral corner of the knee by inducing the development of associated ligaments. J Orthop Sci. 2004, 9:59-65. 10.1007/s00776-003-0739-2

3. Tabira Y, Saga T, Takahashi N, Watanabe K, Nakamura M, Yamaki K: Influence of a fabella in the gastrocnemius muscle on the common fibular nerve in Japanese subjects. Clin Anat. 2013, 26:893-902. 10.1002/ca.22153

4. Duncan W, Dahm DL: Clinical anatomy of the fabella. Clin Anat. 2003, 16:448-449. 10.1002/ca.10137

5. Cherrad T, Louaste J, Bousbaa H, Amhajji L, Khaled R: Fracture of the fabella: an uncommon injury in knee . Case Rep Orthop. 2015, 2015:396710. 10.1155/2015/396710

6. Seol PH, Ha KW, Kim YH, Kwak HJ, Park SW, Ryu BJ: Effect of radial extracorporeal shock wave therapy in patients with fabella syndrome. Ann Rehabil Med. 2016, 40:1124-1128. 10.5535/arm.2016.40.6.1124

7. Kawashima T, Takeishi H, Yoshitomi S, Ito M, Sasaki H: Anatomical study of the fabella, fabellar complex and its clinical implications. Surg Radiol Anat. 2007, 29:611-616. 10.1007/s00276-007-0259-4

8. Zeng SX, Dong XL, Dang RS, et al.: Anatomic study of fabella and its surrounding structures in a Chinese population. Surg Radiol Anat. 2012, 34:65-71. 10.1007/s00276-011-0828-4

9. Egerci OF, Kose O, Turan A, Kilicaslan OF, Sekerci R, Keles-Celik N: Prevalence and distribution of the fabella: a radiographic study in Turkish subjects. Folia Morphol (Warsz). 2017, 76:478-483. 10.5603/FM.a2016.0080

10. Jin ZW, Shibata S, Abe H, Jin Y, Li XW, Murakami G: A new insight into the fabella at knee: the foetal development and evolution. Folia Morphol (Warsz). 2017, 76:87-93. 10.5603/FM.a2016.0048

11. Sarin VK, Erickson GM, Giori NJ, Bergman AG, Carter DR: Coincident development of sesamoid bones and clues to their evolution. Anat Rec. 1999, 257:174-180. 10.1002/(SICI)1097-0185(19991015)257:5<174::AID AR6>3.0.CO;2-O

12. Benjamin M, Ralphs JR: Fibrocartilage in tendons and ligaments--an adaptation to compressive load . J Anat. 1998, 193:481-494. 10.1046/i.1469-7580.1998.19340481.x

13. Seebacher JR, Inglis AE, Marshall JL, Warren RF: The structure of the posterolateral aspect of the knee . J Bone Joint Surg Am. 1982, 64:536-541. 10.2106/00004623-198264040-00008

14. Takebe K, Hirohata K: Peroneal nerve palsy due to fabella. Arch Orthop Trauma Surg. 1981, 99:91-95. 
$10.1007 /$ bf00389743

15. Zipple JT, Hammer RL, Loubert PV: Treatment of fabella syndrome with manual therapy: a case report . J Orthop Sports Phys Ther. 2003, 33:33-39. 10.2519/jospt.2003.33.1.33

16. Weiner DS, Macnab I: The "fabella syndrome": an update. J Pediatr Orthop. 1982, 2:405-408. 10.1097/01241398-198210000-00010

17. Laird L: Fabellar joint causing pain after total knee replacement. J Bone Joint Surg Br. 1991, 73:1007-1008. 10.1302/0301-620x.73b6.1955425

18. Theodorou SJ, Theodorou DJ, Resnick D: Painful stress fractures of the fabella in patients with total knee arthroplasty. AJR Am J Roentgenol. 2005, 185:1141-1144. 10.2214/ajr.04.1230

19. Kuur E: Painful fabella: a case report with review of the literature . Acta Orthop Scand. 1986, 57:453-454. 10.3109/17453678609014771

20. Segal A, Miller TT, Krauss ES: Fabellar snapping as a cause of knee pain after total knee replacement: assessment using dynamic sonography. AJR Am J Roentgenol. 2004, 183:352-354. 10.2214/ajr.183.2.1830352

21. Driessen A, Balke M, Offerhaus C, et al.: The fabella syndrome - a rare cause of posterolateral knee pain: a review of the literature and two case reports. BMC Musculoskelet Disord. 2014, 15:100. 10.1186/1471-247415-100

22. Kim T, Chung H, Lee H, Choi Y, Son JH: A case report and literature review on fabella syndrome after high tibial osteotomy. Medicine (Baltimore). 2018, 97:e9585. 10.1097/md.0000000000009585

23. Ando Y, Miyamoto Y, Tokimura F, et al.: A case report on a very rare variant of popliteal artery entrapment syndrome due to an enlarged fabella associated with severe knee osteoarthritis. J Orthop Sci. 2017, 22:164168. 10.1016/j.jos.2015.06.025

24. Agathangelidis F, Vampertzis T, Gkouliopoulou E, Papastergiou S: Symptomatic enlarged fabella. BMJ Case Rep. 2016, 10.1136/bcr-2016-218085

25. Sakamoto J, Manabe Y, Oyamada J, et al.: Anatomical study of the articular branches innervated the hip and knee joint with reference to mechanism of referral pain in hip joint disease patients. Clin Anat. 2018, 10.1002/ca.23077

26. Çabuk H, Kuşku Çabuk F: Mechanoreceptors of the ligaments and tendons around the knee . Clin Anat. 2016, 29:789-795. 10.1002/ca.22743

27. McDaniel D, Tilton E, Dominick K, et al.: Histological characteristics of knee menisci in patients with osteoarthritis. Clin Anat. 2017, 30:805-810. 10.1002/ca.22920

28. Driban JB, Ward RJ, Eaton CB, Lo GH, Price LL, Lu B, McAlindon TE: Meniscal extrusion or subchondral damage characterize incident accelerated osteoarthritis: data from the osteoarthritis initiative. Clin Anat. 2015, 28:792-799. 10.1002/ca.22590

29. Davis JE, Harkey MS, Ward RJ, et al.: Characterizing the distinct structural changes associated with selfreported knee injury among individuals with incident knee osteoarthritis: data from the osteoarthritis initiative. Clin Anat. 2018, 31:330-334. 10.1002/ca.23054

30. Işik D, Işik Ç, Apaydin N, Üstü Y, Uğurlu M, Bozkurt M: The effect of the dimensions of the distal femur and proximal tibia joint surfaces on the development of knee osteoarthritis. Clin Anat. 2015, 28:672-677. 10.1002/ca.22550

31. Driban JB, Ward RJ, Eaton CB, Lo GH, Price LL, Lu B, McAlindon TE: Meniscal extrusion or subchondral damage characterize incident accelerated osteoarthritis: data from the osteoarthritis initiative. Clin Anat. 2015, 28:792-799. 10.1002/ca.22590

32. Fox AJS, Wanivenhaus F, Burge AJ, Warren RF, Rodeo SA: The human meniscus: a review of anatomy, function, injury, and advances in treatment. Clin Anat. 2015, 28:269-287. 10.1002/ca.22456

33. Davis JE, Harkey MS, Ward RJ, et al.: Characterizing the distinct structural changes associated with selfreported knee injury among individuals with incident knee osteoarthritis: data from the osteoarthritis initiative. Clin Anat. 2018, 31:330-334. 10.1002/ca.23054 